\title{
Article \\ Evaluation of ILEX SelfCerv for Detection of High-Risk Human Papillomavirus Infection in Gynecology Clinic Attendees at a Tertiary Hospital in South Africa
}

\author{
Teboho Amelia Tiiti ${ }^{1,2}{ }^{-}$, Tebogo Loraine Mashishi ${ }^{1}$, Varsetile Varster Nkwinika ${ }^{1,3}$, Kgotlaethata Aaron Molefi ${ }^{4}$, \\ Ina Benoy ${ }^{2,5}$, Johannes Bogers ${ }^{2,5,6}$, Selokela Gloria Selabe ${ }^{1,7}$ and Ramokone Lisbeth Lebelo ${ }^{1,3,7, *(\mathbb{D})}$ \\ 1 Department of Virological Pathology, Sefako Makgatho Health Sciences University, \\ Pretoria 0204, South Africa; tebohotiiti@yahoo.co.za (T.A.T.); mashishitebogolorraine@gmail.com (T.L.M.); \\ vnkwinika@gmail.com (V.V.N.); gloria.selabe@smu.ac.za (S.G.S.) \\ 2 Laboratory of Cell Biology and Histology, Faculty of Medicine and Health Sciences, University of Antwerp, \\ 2610 Antwerpen, Belgium; ibenoy@ambior.org (I.B.); john-paul.bogers@uantwerpen.be (J.B.) \\ 3 South African Vaccination and Immunization Centre, Sefako Makgatho Health Sciences University, \\ Pretoria 0204, South Africa \\ 4 Department of Obstetrics and Gynaecology, Sefako Makgatho Health Sciences University, \\ Pretoria 0204, South Africa; molefi62@yahoo.com \\ 5 Algemeen Medisch Laboratorium (AML), Sonic Healthcare, 2020 Antwerpen, Belgium \\ 6 Department of Anatomical Pathology, Sefako Makgatho Health Sciences University, \\ Pretoria 0204, South Africa \\ check for \\ updates \\ 7 National Health Laboratory Service, Department of Virological Pathology, Sefako Makgatho Health Sciences \\ University, Pretoria 0204, South Africa \\ * Correspondence: ramokone.lebelo@smu.ac.za; Tel.: +27-12521-3038
}

Citation: Tiiti, T.A.; Mashishi, T.L.; Nkwinika, V.V.; Molefi, K.A.; Benoy,

I.; Bogers, J.; Selabe, S.G.; Lebelo, R.L. Evaluation of ILEX SelfCerv for Detection of High-Risk Human Papillomavirus Infection in Gynecology Clinic Attendees at a Tertiary Hospital in South Africa. J. Clin. Med. 2021, 10, 4817. https:// doi.org/10.3390/jcm10214817

Academic Editor: Valeria Ghisetti

Received: 10 August 2021

Accepted: 15 October 2021

Published: 20 October 2021

Publisher's Note: MDPI stays neutral with regard to jurisdictional claims in published maps and institutional affiliations.

Copyright: (c) 2021 by the authors. Licensee MDPI, Basel, Switzerland. This article is an open access article distributed under the terms and conditions of the Creative Commons Attribution (CC BY) license (https:// creativecommons.org/licenses/by/ $4.0 /)$.
Abstract: Background: The SelfCerv Self-Collection Cervical Health Screening Kit (Ilex Medical Ltd., Johannesburg, South Africa) is an applicator tampon designed for self-collection of vaginal samples for the detection of human papillomavirus (HPV) deoxyribonucleic acid (DNA) and E6/E7 messenger ribonucleic acid (mRNA). The study aimed to evaluate the performance of the SelfCerv applicator tampon for the detection of hr-HPV for cervical cancer screening, and further to investigate women's experiences and preferences regarding self-sampling. Methods: Vaginal samples were collected from 527 gynecology clinic attendees aged $\geq 18$ years at a tertiary hospital in Gauteng Province, South Africa. Self-samples were collected using the SelfCerv kit, followed by endocervical samples collected by a healthcare professional using Cervex-Brush ${ }^{\circledR}$ Combi. Participants completed a self-administered questionnaire on self-sampling experiences and preferences. Both samples were tested for 14 highrisk (hr) HPV types and E6/E7 mRNA using the Abbott RealTime HR-HPV and Aptima HR-HPV mRNA assays, respectively. Results: The overall agreement for hr-HPV typing between 527 paired samples was good $(87.1 \% ; \kappa=0.74)$ with high sensitivity $(86.2 \%)$ and specificity $(88.0 \%)$. HPV-16 $(96.4 \% ; \mathrm{k}=0.83)$ had higher agreement rate than HPV-18 $(96.8 \% ; \mathrm{k}=0.72)$ and the other $12 \mathrm{hr}-\mathrm{HPVs}$ $(86.5 \% ; \kappa=0.72)$. Two hundred and eighty-five (285) sample pairs tested for E6/E7 mRNA showed fair agreement $(70.2 \% ; k=0.34)$. Furthermore, self-sampling was reported as comfortable $(90.5 \%)$ and painless $(86.7 \%)$, with $88.4 \%$ of women preferring self-collection. Conclusions: Self-collected samples had good agreement with the healthcare professional-collected samples for the detection of hr-HPV DNA and the procedure was highly preferred by women. Self-sampling using SelfCerv can be used as an alternative to healthcare professional sampling in clinic-based routine cervical cancer screening.

Keywords: South Africa; SelfCerv; HPV; cervical cancer; self-sampling; E6/E7 mRNA; preference

\section{Introduction}

Cervical cancer is one of the most preventable and treatable diseases. However, there were an estimated 604,127 new cervical cancer cases and 341,831 deaths in 2020 
worldwide [1]. Several programs have been implemented to curb cervical cancer numbers. For instance, Papanicolaou (Pap) testing has significantly reduced cervical cancer incidence and mortality rates, particularly in high-income countries (HIC) [2]. However, in lowand middle-income countries (LMICs), Pap testing has been unsuccessful because of poor organization, low coverage, and lack of quality assurance [2]. To achieve cervical cancer screening coverage, the implementation of affordable and acceptable screening and treatment services must be explored [3].

Persistent infection with one of the oncogenic types of human papillomavirus (HPV), primarily types 16 and 18, is a necessary but not sufficient cause of cervical cancer [2]. The role of HPV in cervical cancer has therefore led to the development of molecular HPV tests [4]. HPV testing has a higher sensitivity than cytology for detecting high-grade precancerous lesions, and is, therefore, the best tool for cervical cancer screening $[5,6]$. Moreover, unlike Pap smear, HPV testing enables women to self-collect cervicovaginal samples that may improve cervical cancer screening attendance [7].

A self-collected sample is an easy to perform, preferred, and comfortable sampling method that is increasingly adopted for the detection of HPV [8,9]. Several studies have reported the advantages of self-collection as being less costly, noninvasive, and wellaccepted [10-13]. Compared to healthcare professional-collected samples, self-collected samples for HPV detection have a concordance of 89.2-94.2\% [8,9], reliability (measured using the kappa statistic $[\kappa]) \geq 0.7[8,9,14]$, sensitivity $\geq 80 \%$ and specificity $>90 \%[8,9,13]$. Using the hr-HPV assay (polymerase chain reaction), self-samples have similar sensitivity; however, they have slightly less specificity compared to healthcare professional-collected samples [15]. There are several self-collection devices, such as brushes, swabs, and lavages, which have been developed and clinically tested for HPV testing in cervical cancer screening. The SelfCerv (Ilex Medical Ltd., Johannesburg, South Africa) applicator tampon is an improved device for discreet, easy use and handling to avoid contamination during use. Several studies have shown that the application of self-sampling devices has increased cervical cancer screening attendance and coverage [16-18]. Moreover, a meta-analysis in 2018 reported higher response rates for hr-HPV testing when using self-sampling kits [15]. Therefore, self-collection can be an alternative method to encourage attendance in cervical cancer screening programs. Hence, in South Africa, the National Department of Health (NDoH) Cervical Cancer Prevention and Control Policy recommends the investigation of self-sampling as a tool to increase cervical cancer screening coverage in several settings, particularly among harder to reach populations [19].

This study aimed to evaluate the performance of the SelfCerv Self-Collection Cervical Health Screening applicator tampon compared to health professional-collected samples for the detection of hr-HPV for cervical cancer screening, and further, to investigate women's experiences and preferences regarding self-sampling versus healthcare professional sampling.

\section{Materials and Methods}

\subsection{Study Design and Population}

This was a cross-sectional study conducted at a tertiary hospital in Gauteng Province, South Africa, between 2016 and 2018. Paired samples were collected from 527 women who were enrolled in the study following obtaining written informed consent. Samples were sent to the HPV and STIs Training Centre for Africa at the Department of Virology laboratory for testing. Women aged 18 years and older were included in the study, and those who had undergone a complete hysterectomy or were going through their monthly menstrual cycle were excluded.

\subsection{Specimen Collection}

Participants received verbal instructions on how to collect the self-sample using a SelfCerv Self Collection Cervical Health Screening Kit (Ilex Medical Ltd., Johannesburg, South Africa). The SelfCerv package included pictorial diagrams and instructions for 
use. The SelfCerv Kit includes an applicator tampon, a patient information sticker, and a specimen bottle containing $4 \mathrm{~mL}$ of saline buffer. While waiting to be attended to at the clinic, consenting participants were individually taken to a private room and asked to insert the applicator tampon into the vagina until it met with resistance, and then remove the applicator and return to the waiting room. Participants then completed part 1 of the questionnaire. After tampon insertion for two hours, as specified by the manufacturer, the participants were requested by the healthcare professional to remove the tampon, taking care not to touch the tampon with their hands. The tampon has a cord/string that was gently pulled to remove it from the vagina and place it in a specimen bottle containing the saline buffer, making sure that the cord/string remained outside the bottle. To avoid contamination, there was no direct contact of the tampon with the hands during insertion and removal of the tampon. The healthcare professional then examined the participants and obtained an endocervical sample using a Cervex-Brush ${ }^{\circledR}$ Combi (Rovers Medical Devices, B.V., Oss, The Netherlands) with the assistance of a speculum. The collection brush containing endocervical cells was immediately rinsed into a ThinPrep PreservCyt solution vial (Hologic Incorporated, Bedford, MA, USA) and then discarded. Participants were then requested to complete the self-sampling part of the questionnaire. Both samples were placed in a medical box and transported to the laboratory for processing. Upon arrival, $20 \mathrm{~mL}$ of ThinPrep PreservCyt solution was added to the specimen bottle containing the tampon. The bottle was swirled and then squeezed to remove the tampon from the bottle. The solution from the specimen bottle was transferred into an empty ThinPrep vial and the vial was labeled properly.

\subsection{Data Collection}

The questionnaire consisted of four main parts. The first part of the questionnaire collected demographic data including age, marital and employment status, place of residence, race, sexual practices, and reproductive history. The second and third parts included questions on HPV and cervical cancer. The fourth part included six closed-ended (Yes/No) questions to evaluate the participant's experiences and preferences using the selfsampling device. Participants were asked to fill in part 4 of the questionnaire, which was on self-sampling experiences and preferences after they had self-collected and a healthcare professional had taken the sample. The questions to assess self-sampling experiences and preferences were: "Were you comfortable using the self-collection device?", "Did you experience any pain when self-collecting the sample?", "Would you prefer to self-collect the sample for cervical cancer screening in the future?", "Would you prefer to use the self-collection device to collect a sample for cervical cancer screening in the future?", "Would you prefer the healthcare professional to take the sample for cervical cancer screening"? "Are you worried that you have not collected the sample properly?". The data were double entered into Microsoft Excel.

\subsection{Analysis of Samples for the Presence of High-Risk HPVs}

HPV genotyping was performed using Abbott RealTime High-Risk (HR) HPV assay (Abbott Molecular GmbH \& Co. KG, Wiesbaden, Germany) according to the manufacturer's instructions. A volume of $0.8 \mathrm{~mL}$ of self-collected and healthcare professionalcollected samples from each ThinPrep PreservCyt vial was transferred into Abbott Master Mix tubes and labeled properly. This assay detects 14 high-risk HPV types (16, 18, 31, 33, 35, $39,45,51,52,56,58,59,66$, and 68) and only genotypes HPV-16 and HPV-18 from the other $12 \mathrm{hr}-\mathrm{HPV}$ types. Probes for HPV-16 and HPV-18, "other hr-HPV" types $(31,33,35,39,45$, $51,52,56,58,59,66$, and 68) and IC were labeled with four fluorophores allowing their signals to be distinguishable in a single reaction to differentiate HPV-16 and HPV-18 from other 12 hr-HPVs. The HPV target cutoff (32.00 cycle threshold $(\mathrm{Ct}))$ as well as the internal control target cutoff $(35.00 \mathrm{Ct})$ is already established by the manufacturer. Samples with insufficient content of cervical samples are automatically invalidated. The endogenous human beta-globin sequence was detected as sample validity control for cell adequacy 


\subsection{Analysis of Samples for HPV E6/E7 mRNA}

The Aptima HPV mRNA assay (Hologic Gen-Probe, Inc., San Diego, CA, United States) was used to detect E6/E7 viral mRNA from $14 \mathrm{hr}-\mathrm{HPV}$ types $(16,18,31,33,35,39,45,51,52$, $56,58,59,66$ and 68). Briefly, an aliquot of $1 \mathrm{~mL}$ was transferred into the Aptima Specimen Transfer Tube containing specimen transport media that lyses the cells and releases the mRNA and protects it from degradation. During testing, the mRNA was isolated from the specimen using capture oligomers that are linked to magnetic microparticles. Sequences complementary to specific regions of the HPV mRNA target molecules and a string of deoxyadenosine residues were contained in the capture oligomers. Sequence-specific regions of the capture oligomers bind to specific regions of the HPV mRNA target molecule during the hybridization step. HPV mRNA was amplified using transcription-based nucleic acid amplification and detection was achieved by Hybridization Protection Assay. Assay results were interpreted on the basis of the signal/cutoff ratio for the analyte, and specimens with signal/cutoff ratios of $\geq 0.5$ were considered positive.

\subsection{Data Analysis}

Data analysis was performed using STATA version 14.1 (Stata Corp., College Station, TX, USA). Results of categorical data were presented as frequencies and percentages. For continuous data (age), mean and standard deviation (SD) were calculated. The overall agreement (percent agreement, kappa values with 95\% confidence intervals) was determined using the kappa $(\kappa)$ statistic. Kappa values were considered as poor $(\leq 0.20)$, fair (0.21-0.4), moderate (0.41-0.60), good (0.61-0.80), and very good (0.81-1.00). Healthcare professional-collected test results were used as a reference standard to estimate the sensitivity and specificity of the applicator-tampon collection method.

\section{Results}

\subsection{Demographic Characteristics of Study Participants}

The mean ( \pm standard deviation (SD)) age of participants was 36.8 (SD: \pm 11.0 ; range 18-68) years. Most (32.6\%) of the participants were between the ages of 30 and 39, followed by those aged less than 30 years $(28.7 \%)$. The majority $(75.9 \%)$ of the participants were either single and/or divorced/widowed/separated, $54.8 \%$ were unemployed, and $85.0 \%$ were from semi-urban areas. Most (99.6\%) of the participants were black Africans and $52.8 \%$ reported never being screened for cervical cancer before the study. The majority $(44.2 \%)$ of the participants attended the clinic for routine Pap smear with the least $(5.7 \%)$ of the participants seeking family planning services. The study population included $66.4 \%$ of women who were asymptomatic (Table 1).

\subsection{Performance of HPV Self-Sampling Relative to Healthcare Professional Sampling}

DNA extraction and amplification was successfully achieved on all paired samples, as indicated with a positive internal control. For self-collected samples, the overall HPV prevalence was $47.6 \%$ (251/527); for healthcare professional-collected samples, $48.0 \%$ (253/527). HPV-16 in self-collected samples and healthcare professional-collected samples were detected in $63(12.0 \%)$ and $62(11.7 \%)$, respectively. Self-collection detected $6.5 \%$ $(34 / 527)$ and $42.1 \%(222 / 527)$ for HPV-18 and other $12 \mathrm{hr}-\mathrm{HPVs}$ compared to 5.9\% (31/527) and $41.9 \%(221 / 527)$ by healthcare professional sampling. The results for hr-HPV DNA and HPV E6/E7 mRNA testing were obtained for 527 and 285 participants, respectively (Table 2). Overall, the percent agreement for detection of hr-HPV DNA was $87.1 \%$, and the Cohen $(\mathrm{k})$ coefficient was 0.74 for agreement between self-and healthcare professionalcollected samples. Compared with the healthcare professional-collected samples, selfcollected samples demonstrated high sensitivity $(86.2 \%)$ and specificity $(88.0 \%)$ for the detection of overall hr-HPV DNA, respectively. Overall, there were 68 discordant samples, 33 were negative by healthcare professional sampling, but positive by self-sampling, and 35 were negative by self-sampling, but positive by healthcare professional sampling. For HPV-16, the agreement was very good $(96.4 \%$; $k=0.83)$ compared to HPV-18 (good; $(96.8 \%$; 
$\mathrm{K}=0.72)$ ). Self-samples for the detection of HPV-16 demonstrated high specificity $(97.9 \%)$. The sensitivity (77.4\%) was lower in self-collected samples for HPV-18 detection but had comparable specificity $(98.0 \%)$ to that for HPV-16 (97.9\%). Other $12 \mathrm{hr}-\mathrm{HPVs}$ detection in self-collected samples had a concordance of $86.5 \%(\kappa=0.72)$. For the other $12 \mathrm{hr}-\mathrm{HPVs}$, the sensitivity and specificity were $84.2 \%$ and $88.2 \%$, respectively. For HPV E6/E7 mRNA, self-collected samples demonstrated a fair level of agreement $(70.2 \% ; \kappa=0.34)$, sensitivity $(68.3 \%)$, and specificity $(77.1 \%)$.

Table 1. Demographic characteristics of the study participants $(n=527)$.

\begin{tabular}{|c|c|c|}
\hline Variables & $n$ & $\%$ \\
\hline \multicolumn{3}{|l|}{ Age in years } \\
\hline $18-29$ & 151 & 28.7 \\
\hline $30-39$ & 172 & 32.6 \\
\hline $40-49$ & 121 & 23.0 \\
\hline $50-59$ & 61 & 11.6 \\
\hline$\geq 60$ & 19 & 3.6 \\
\hline Unspecified & 3 & 0.6 \\
\hline \multicolumn{3}{|l|}{ Marital Status } \\
\hline Single & 354 & 67.2 \\
\hline Married & 126 & 23.9 \\
\hline Divorced/Widowed/Separated & 46 & 8.7 \\
\hline Unspecified & 1 & 0.2 \\
\hline \multicolumn{3}{|l|}{ Employment Status } \\
\hline Employed & 237 & 45.0 \\
\hline Unemployed & 289 & 54.8 \\
\hline Unspecified & 1 & 0.2 \\
\hline \multicolumn{3}{|l|}{ Place of residence } \\
\hline Rural & 12 & 2.3 \\
\hline Semi-Urban & 448 & 85.0 \\
\hline Urban & 63 & 12.0 \\
\hline Unspecified & 4 & 0.8 \\
\hline \multicolumn{3}{|l|}{ Race } \\
\hline African & 525 & 99.6 \\
\hline Other & 2 & 0.4 \\
\hline \multicolumn{3}{|l|}{ Pap screening before } \\
\hline Screened & 248 & 47.1 \\
\hline Not screened & 278 & 52.8 \\
\hline Unspecified & 1 & 0.2 \\
\hline \multicolumn{3}{|l|}{ Reason for visit } \\
\hline Family planning & 30 & 5.7 \\
\hline Routine Pap smear & 233 & 44.2 \\
\hline Termination of pregnancy & 87 & 16.5 \\
\hline Colposcopy & 33 & 6.3 \\
\hline LLETZ & 87 & 16.5 \\
\hline Review with Pap smear after LLETZ & 57 & 10.8 \\
\hline
\end{tabular}

Asymptomatic: Family planning; Routine Pap smear; Termination of pregnancy. 
Table 2. Performance of hr-HPV and HPVE6/E7 mRNA self-sampling relative to healthcare professional sampling.

\begin{tabular}{|c|c|c|c|c|c|c|c|}
\hline Self-Collection & Healthc & Professiona & lection & $\begin{array}{c}\% \\
\text { Agreement }\end{array}$ & $\begin{array}{l}\text { Sensitivity } \\
(95 \% \mathrm{CI})\end{array}$ & $\begin{array}{l}\text { Specificity } \\
(95 \% \text { CI) }\end{array}$ & $\begin{array}{c}\text { K Statistics } \\
(95 \% \mathrm{CI})\end{array}$ \\
\hline $\begin{array}{l}\text { Overall hr-HPV } \\
\text { DNA }\end{array}$ & Positive & Negative & Total & \multirow{4}{*}{87.1} & \multirow{4}{*}{$\begin{array}{c}86.2 \\
(81.3-90.2)\end{array}$} & \multirow{4}{*}{$\begin{array}{c}88.0 \\
(83.5-91.6)\end{array}$} & \multirow{4}{*}{$\begin{array}{c}0.74 \\
(0.68-0.80\end{array}$} \\
\hline Positive & 218 & 33 & 251 & & & & \\
\hline Negative & 35 & 241 & 276 & & & & \\
\hline Total & 253 & 274 & 527 & & & & \\
\hline HPV-16 & Positive & Negative & Total & \multirow{4}{*}{96.4} & \multirow{4}{*}{$\begin{array}{c}85.5 \\
(74.2-93.1)\end{array}$} & \multirow{4}{*}{$\begin{array}{c}97.9 \\
(96.1-99.0)\end{array}$} & \multirow{4}{*}{$\begin{array}{c}0.83 \\
(0.75-0.90)\end{array}$} \\
\hline Positive & 53 & 10 & 63 & & & & \\
\hline Negative & 9 & 455 & 464 & & & & \\
\hline Total & 62 & 465 & 527 & & & & \\
\hline HPV-18 & Positive & Negative & Total & \multirow{4}{*}{96.8} & \multirow{4}{*}{$\begin{array}{c}77.4 \\
(58.9-90.4)\end{array}$} & \multirow{4}{*}{$\begin{array}{c}98.0 \\
(96.3-99.0)\end{array}$} & \multirow{4}{*}{$\begin{array}{c}0.72 \\
(0.59-0.85)\end{array}$} \\
\hline Positive & 24 & 10 & 34 & & & & \\
\hline Negative & 7 & 486 & 493 & & & & \\
\hline Total & 31 & 496 & 527 & & & & \\
\hline Other 12 hr-HPVs & Positive & Negative & Total & \multirow{4}{*}{86.5} & \multirow{4}{*}{$\begin{array}{c}84.2 \\
(78.7-88.7)\end{array}$} & \multirow{4}{*}{$\begin{array}{c}88.2 \\
(84.1-91.6\end{array}$} & \multirow{4}{*}{$\begin{array}{c}0.72 \\
(0.66-0.78\end{array}$} \\
\hline Positive & 186 & 36 & 222 & & & & \\
\hline Negative & 35 & 270 & 305 & & & & \\
\hline Total & 221 & 306 & 527 & & & & \\
\hline HPV E6/E7 mRNA & Positive & Negative & Total & \multirow{4}{*}{70.2} & \multirow{4}{*}{$\begin{array}{c}68.3 \\
(61.8-74.3)\end{array}$} & \multirow{4}{*}{$\begin{array}{c}77.1 \\
(64.5-86.9)\end{array}$} & \multirow{4}{*}{$\begin{array}{c}0.34 \\
(0.22-0.46)\end{array}$} \\
\hline Positive & 153 & 14 & 167 & & & & \\
\hline Negative & 71 & 47 & 118 & & & & \\
\hline Total & 224 & 61 & 285 & & & & \\
\hline
\end{tabular}

HR-HPV: high-risk human papillomavirus.

\subsection{Discordant hr-HPV Test Results}

There were 19 disagreements between self and healthcare professional HPV tests for HPV-16, 17 disagreements for HPV-18, and 71 for other $12 \mathrm{hr}$-HPVs. Of all disagreements, $56 / 107(52.3 \%)$ results were positive for self-collected samples and negative for the healthcare professional-collected samples. No follow-up is available for these women. Discrepant self-collected test results were positive at high cycle threshold values (Table 3).

Table 3. Comparison of Abbott m2000 hr-HPV test results using paired self- and healthcare professional-collected samples.

\begin{tabular}{cccc}
\hline HPV Type & $\begin{array}{c}\text { No. of Disagreements } \\
\text { between Self-Collected and } \\
\text { Healthcare } \\
\text { Professional-Collected Test } \\
\text { Results }\end{array}$ & $\begin{array}{c}\text { No. of Disagreements for } \\
\text { Which Self-Collected Vaginal } \\
\text { Test Result Was Positive and } \\
\text { Healthcare }\end{array}$ & $\begin{array}{c}\text { Mean Cycle Threshold (ct) } \\
\text { Where Self-Collected Sample } \\
\text { Test Result Was Positive and } \\
\text { the Healthcare Professional } \\
\text { Test Result Was Negative } \\
\text { Test Result Was Negative (\%) }\end{array}$ \\
\hline HPV-16 & 19 & $10(52.6)$ & 24.43 \\
\hline HPV-18 & 17 & $10(58.8)$ & 26.45 \\
\hline Other 12 hr-HPVs & 71 & $36(50.7)$ & 25.85 \\
\hline
\end{tabular}

\subsection{Women's Experience and Preference for Self-Sampling}

A total of 526 out of 527 participants answered the questionnaire. Self-sampling using the SelfCerv was recorded as comfortable by $90.5 \%$ while $13.3 \%$ recorded experiencing pain. Most participants reported that they would prefer to use the SelfCerv self-sampling device $(88.4 \%)$ or self-collect the sample $(87.1 \%)$ regardless of the device. A total of 402 $(76.4 \%)$ participants recorded that they would also prefer the healthcare professional to 
collect the sample. Very few participants $(24.3 \%)$ were worried that they did not collect the sample properly (Table 4 ).

Table 4. Experience and preferences of self-sampling $(n=526)$.

\begin{tabular}{|c|c|c|}
\hline Category & $n$ & $\%$ \\
\hline \multicolumn{3}{|c|}{$\begin{array}{l}\text { Were you comfortable using the self-collection } \\
\text { device? }\end{array}$} \\
\hline Yes & 476 & 90.5 \\
\hline No & 50 & 9.5 \\
\hline \multicolumn{3}{|c|}{$\begin{array}{l}\text { Did you experience any pain when } \\
\text { self-collecting the sample? }\end{array}$} \\
\hline Yes & 70 & 13.3 \\
\hline No & 456 & 86.7 \\
\hline \multicolumn{3}{|c|}{$\begin{array}{l}\text { Would you prefer to self-collect the sample for } \\
\text { cervical cancer screening in the future? }\end{array}$} \\
\hline Yes & 458 & 87.1 \\
\hline No & 68 & 12.9 \\
\hline \multicolumn{3}{|c|}{$\begin{array}{l}\text { Would you prefer to use the self-collection } \\
\text { device to collect a sample for cervical cancer } \\
\text { screening in the future? }\end{array}$} \\
\hline Yes & 465 & 88.4 \\
\hline No & 61 & 11.6 \\
\hline \multicolumn{3}{|c|}{$\begin{array}{l}\text { Would you prefer the healthcare professional to } \\
\text { take the sample for cervical cancer screening? }\end{array}$} \\
\hline Yes & 402 & 76.4 \\
\hline No & 124 & 23.6 \\
\hline \multicolumn{3}{|c|}{$\begin{array}{l}\text { Are you worried that you have not collected the } \\
\text { sample properly? }\end{array}$} \\
\hline Yes & 128 & 24.3 \\
\hline No & 398 & 75.7 \\
\hline
\end{tabular}

\subsection{Women's Experience and Preference for Self-Sampling by Age Group and Screening}

As shown in Table 5, women aged 40-49 and 50-59 years were more likely to be comfortable with using the self-collection device than the other age groups. Comfortability using the SelfCerv device was statistically associated with age $(p=0.007)$. The results further show that women aged $40-49$ years were more likely to prefer the healthcare professional to collect the sample. Women in the age group 60 years and older were less worried that they had not collected the sample properly but more likely to have experienced pain when self-collecting the sample. A low proportion (12.6\%) of participants who have never been screened before the study recorded not being comfortable using the self-collection device. Most unscreened participants (86.0\%) recorded not having experienced pain during self-collection. The majority (89.9\%) of participants who had never been screened recorded that they would prefer to use the self-collection device (SelfCerv) for future cervical cancer screening, as opposed to $28(10.1 \%)$ who answered "no" to the question. 
Table 5. Experience and preferences of self-sampling by age group and screening.

\begin{tabular}{|c|c|c|c|c|c|c|c|}
\hline \multirow{2}{*}{ Category } & & \multicolumn{6}{|c|}{ Age (Years) } \\
\hline & & $<30$ & $30-39$ & $40-49$ & $50-59$ & $60+$ & $p$-Value \\
\hline \multirow{2}{*}{$\begin{array}{l}\text { Were you comfortable using the self-collection } \\
\text { device? }\end{array}$} & Yes & $132(87.4)$ & $152(88.9)$ & $113(93.4)$ & $61(100)$ & $16(84.2)$ & \multirow[b]{2}{*}{0.007} \\
\hline & No & 19 (12.6) & 19 (11.1) & $8(76.6)$ & - & $3(15.8)$ & \\
\hline \multirow{2}{*}{$\begin{array}{l}\text { Would you prefer to self-collect the sample for } \\
\text { cervical cancer screening in the future? }\end{array}$} & Yes & $132(87.4)$ & 149 (87.1) & $103(85.1)$ & $55(90.2)$ & 17 (89.5) & \multirow{2}{*}{0.932} \\
\hline & No & 19 (12.6) & 22 (12.9) & $18(14.9)$ & $6(9.8)$ & $2(10.5)$ & \\
\hline \multirow{2}{*}{$\begin{array}{l}\text { Would you prefer the healthcare professional to } \\
\text { take the sample for cervical cancer screening? }\end{array}$} & Yes & $32(21.2)$ & $39(22.8)$ & 35 (28.9) & $14(22.9)$ & $4(21.0)$ & \multirow{2}{*}{0.658} \\
\hline & No & $119(78.8)$ & $132(77.2)$ & 86 (71.1) & 47 (77.1) & $15(79.0)$ & \\
\hline \multirow{2}{*}{$\begin{array}{l}\text { Are you worried that you have not collected the } \\
\text { sample properly? }\end{array}$} & Yes & $43(28.5)$ & $43(25.1)$ & 24 (19.8) & 15 (24.6) & $2(10.5)$ & \multirow{2}{*}{0.329} \\
\hline & No & $108(71.5)$ & $128(74.9)$ & $97(80.2)$ & $46(75.4)$ & $17(89.5)$ & \\
\hline \multirow{2}{*}{$\begin{array}{l}\text { Did you experience any pain when } \\
\text { self-collecting the sample? }\end{array}$} & Yes & $26(17.2)$ & $23(13.4)$ & $13(10.7)$ & $4(6.6)$ & $4(21.0)$ & \multirow{2}{*}{0.174} \\
\hline & No & $125(82.8)$ & $148(86.6)$ & $108(89.3)$ & 57 (93.4) & $15(79.0)$ & \\
\hline \multirow{2}{*}{$\begin{array}{l}\text { Would you prefer to use the self-collection } \\
\text { device to collect a sample for cervical cancer } \\
\text { screening in the future? }\end{array}$} & Yes & $134(88.7)$ & $149(87.1)$ & $108(89.3)$ & $54(88.5)$ & 18 (94.7) & \multirow{2}{*}{0.946} \\
\hline & No & 17 (11.3) & $22(12.9)$ & $13(10.7)$ & 7 (11.5) & $1(5.3)$ & \\
\hline \multirow[b]{2}{*}{ Category } & \multicolumn{7}{|c|}{ Pap screening } \\
\hline & & Screened & $\begin{array}{c}\text { Never } \\
\text { screened }\end{array}$ & & & & $p$-value \\
\hline \multirow{2}{*}{$\begin{array}{l}\text { Were you comfortable using the self-collection } \\
\text { device? }\end{array}$} & Yes & $233(94.00)$ & 243 (87.4) & & & & \multirow{2}{*}{0.011} \\
\hline & No & $15(6.0)$ & 35 (12.6) & & & & \\
\hline \multirow{2}{*}{$\begin{array}{l}\text { Would you prefer to self-collect the sample for } \\
\text { cervical cancer screening in the future? }\end{array}$} & Yes & $214(86.3)$ & $244(87.8)$ & & & & \multirow{2}{*}{0.614} \\
\hline & No & 34 (13.7) & 34 (12.2) & & & & \\
\hline \multirow{2}{*}{$\begin{array}{l}\text { Would you prefer the healthcare professional to } \\
\text { take the sample for cervical cancer screening? }\end{array}$} & Yes & $193(77.8)$ & $209(75.2)$ & & & & \multirow{2}{*}{0.476} \\
\hline & No & $55(22.2)$ & $69(24.8)$ & & & & \\
\hline \multirow{2}{*}{$\begin{array}{l}\text { Are you worried that you have not collected the } \\
\text { sample properly? }\end{array}$} & Yes & 49 (19.8) & $79(28.4)$ & & & & \multirow{2}{*}{0.021} \\
\hline & No & $199(80.2)$ & $199(71.6)$ & & & & \\
\hline \multirow{2}{*}{$\begin{array}{l}\text { Did you experience any pain when } \\
\text { self-collecting the sample? }\end{array}$} & Yes & 31 (12.5) & $39(14.0)$ & & & & \multirow{2}{*}{0.606} \\
\hline & No & 217 (87.5) & $239(86.0)$ & & & & \\
\hline \multirow{2}{*}{$\begin{array}{l}\text { Would you prefer to use the self-collection } \\
\text { device to collect a sample for cervical cancer } \\
\text { screening in the future? }\end{array}$} & Yes & $215(86.7)$ & $250(89.9)$ & & & & \multirow{2}{*}{0.247} \\
\hline & No & 33 (13.3) & $28(10.1)$ & & & & \\
\hline
\end{tabular}

\section{Discussion}

Interventions to increase cervical cancer screening coverage are important. This is supported by the data from the current study, which show that the majority of women in the current study had never been screened for cervical cancer using the Pap test at the time of the study. The reasons why these women had never been screened were not explored. In HPV self-sampling, sample validity depends on the participants; hence, it is important to compare HPV test results from self-collected samples with those collected by a healthcare professional, which are considered the gold standard.

The current study revealed $87.1 \%$ concordance between self-and healthcare professionalcollected samples in detecting overall hr-HPV with $\mathrm{k} 0.74$, which showed good agreement. The level of agreement in our study was not as high as that in a study in Ghana among 194 women using the careHPV brush coupled with the careHPV assay [8]. Other studies revealed a similar level of agreement as in our study; $\mathrm{k:0.75} \mathrm{[20],} \mathrm{\kappa :} 0.74$ [21], and $\mathrm{k:} 0.71$ [22] However, other studies in Ethiopia ( $\kappa: 0.58$ ) [23] and Cameroon ( $\kappa: 0.52)$ [24] reported a lower level of agreement compared to our study. It is uncertain if these differences reflect the different self-sampling devices used, HPV testing methods, population, and/or sample size. Regarding false-positive results by self-sampling, the tampon might have picked up vulvovaginal HPV infection. Regarding individual HPV types, the level of agreement for HPV-16 was very good, with a concordance of $96.4 \%$ and $\kappa: 0.83$ compared to HPV-18 $(96.8 \% ; \mathrm{k}=0.72)$ and the other $12 \mathrm{hr}-\mathrm{HPV}(86.5 \%$; $\mathrm{k}$ : 0.72). It might be that HPV-16 is present in higher loads compared to the other types and therefore easily recoverable even following DNA loss during transportation, processing, and storage. The level of agreement 
for HPV-16 and HPV-18 in our study is consistent with a South African study that used non-applicator tampons and demonstrated a very good ( $\mathrm{k}: 0.88)$ and good ( $\mathrm{\kappa}: 0.80)$ level of agreement, respectively [25]. However, the level of agreement for HPV-16 and HPV-18 in our study was high compared to a previous study that reported $\mathrm{k}: 0.72$ and $\mathrm{\kappa}: 0.48$ for HPV-16 and HPV-18, respectively [26].

For overall hr-HPV, the sensitivity and specificity of self-collected samples compared with healthcare professional-collected samples were $86.2 \%$ and $88.0 \%$, respectively. Similar findings were reported in a study conducted among women with reproductive tract infections using Roche Reverse Line Blot Assay [25]. In Malawi, Esber et al. [13] in 2018 reported a lower sensitivity (79\%); however, they also reported higher specificity (99\%) compared to our findings. In our study, the sensitivity of self-collected samples for HPV-16 $(85.5 \%)$ was higher than $75 \%$, and the specificity $(97.9 \%)$ was comparable to the $100 \%$ reported in a previous study [13]. The sensitivity and specificity for the other $12 \mathrm{hr}-\mathrm{HPVs}$ in the current study were similar to that previously reported in Japan [27].

There are limited data on the performance of self-collected samples for hr-HPV mRNA detection. In the current study, the SelfCerv applicator tampon coupled with Aptima HR-HPV mRNA assay demonstrated a fair level of agreement (70.2\%; k: 0.34). In South Africa and Kenya, Adamson et al. [28] and Senkomago et al. [29] found 77.6-82.8\% concordance with $\mathrm{\kappa}$ : 0.54-0.55, which represented moderate agreement between these two methods. Adamson et al. [28] reported high sensitivity (77.4\%); however, they reported similar specificity (77.4\%) compared to the current study. Arbyn et al. [30], in a metaanalysis, reported that self-samples were less sensitive and specific with signal-based assays. Toliman et al. [31] also reported low sensitivity of self-collected samples using the Aptima HR-HPV assay. Furthermore, in a recent meta-analysis, Arbyn et al. [15] reported that mRNA testing using Aptima was less sensitive but as specific in self-collected samples. These results may be due to the sampling location, as the speculum-assisted health professional samples are collected from the cervix directly in the transformation zone, whereas the applicator tampon collects a mix of exfoliated cervical and vaginal cells. The self-collected samples may not have a substantial number of cells from the transformation zone that are infected and have a replicating virus.

In the current study, the majority of participants were comfortable self-collecting the sample using the SelfCerv applicator tampon. Consistent with previous studies, participants reported self-sampling as being painless when using nylon-tipped flocked swabs and flocked swabs $[32,33]$ and comfortable when using self-sampling devices such as Evalyn brushes, flocked swabs, and Dacron swabs $[9,33,34]$. However, there were conflicting findings, since some of the participants who had reported self-sampling using the applicator tampon being comfortable but also reported experiencing pain. In the current study, participants between the ages 40-59 were more comfortable using the SelfCerv device for collection compared to the other groups. The painful and uncomfortable experience reported by the minority of participants in our study might be explained by the physical characteristics of the applicator tampon. The tampon has a cardboard applicator that allows women to push the tampon inside the vagina; the applicator may contribute to discomfort and pain, particularly if an individual is not familiar with the device and thus unable to insert it properly. In older women, the vaginal lining thins and dries out; this might explain the pain experienced by women 60 years and older in the study. Among participants who had never been screened for cervical cancer before, there was a positive response towards the self-sampling experience, as the majority showed interest to use the device for future screening.

Although a high proportion of participants preferred the self-sampling method and were willing to self-sample again, some participants were still worried about having correctly collected the sample, which is a common concern that has previously been reported [13,34]. Despite the high number of participants who preferred the self-sampling method, participants still indicated that they also preferred the samples to be collected by a healthcare professional. This could be because participants were not asked to choose 
one preferred method over the other. Although participants were confident and found self-sampling painless, they still preferred a more experienced individual (i.e., a healthcare professional) to collect the samples. Although the NDoH in South Africa recommends self-sampling, particularly to increase coverage among harder to reach populations, the SelfCerv might not be an ideal device for non-clinic-based settings considering the logistics of transporting the device from the point of collection to the testing laboratory. Domque et al. [35], in 2020, among women from remote villages in Cameroon reported a feasible and appropriate population-based test-and-treat cervical screening strategy using self-sampling for HPV testing. The study took an approach of having health promoters and women's health program staff visit rural villages to educate women about self-sampling and HPV testing, whereby women provided a self-sample that was thereafter taken to the laboratory for testing [35]. Therefore, the feasibility, effectiveness, and cost-effectiveness of the SelfCerv should further be investigated in the context of screening, particularly among harder to reach populations.

\section{Limitations}

Since only 285-paired samples were tested, this could have affected the results. The questionnaire employed in the study did not include a question assessing the educational level of participants, nor did it assess any difficulties experienced during the insertion and/or removal of the tampon.

\section{Conclusions}

The study shows that self-sampling using an applicator tampon was comparable to healthcare professional-collected samples in detecting hr-HPV DNA using the Abbott hr-HPV assay. However, the self-collected samples demonstrated a fair level of agreement for HPV E6 and E7 mRNA. Furthermore, we report a positive experience and a high preference for clinic-based self-sampling using the applicator tampon, which could be a way to increase primary screening coverage among women with limited access to screening services. The findings of the study must be interpreted with caution, as the SelfCerv might not be transferable to "harder-to-reach" populations who are often underscreened or not screened at all. Further research is needed to evaluate the effectiveness of applicator tampon-based self-collection and HPV testing for true cervical disease.

Author Contributions: Conceptualization, T.A.T., I.B., J.B., S.G.S. and R.L.L.; Data curation, T.A.T., T.L.M., V.V.N., K.A.M. and R.L.L.; Formal analysis, T.A.T.; Funding acquisition, J.B., S.G.S. and R.L.L.; Investigation, T.A.T., T.L.M., V.V.N., K.A.M., I.B., J.B., S.G.S. and R.L.L.; Methodology, T.A.T., T.L.M., V.V.N., K.A.M., I.B., J.B., S.G.S. and R.L.L.; Project administration, T.A.T., T.L.M., V.V.N., K.A.M., I.B., J.B., S.G.S. and R.L.L.; Resources, T.A.T., I.B., J.B., S.G.S. and R.L.L.; Supervision, I.B., J.B., S.G.S. and R.L.L.; Visualization, T.A.T., J.B., S.G.S. and R.L.L.; Writing—original draft, T.A.T.; Writing-review and editing, T.A.T., T.L.M., V.V.N., K.A.M., I.B., J.B., S.G.S. and R.L.L. All authors have read and agreed to the published version of the manuscript.

Funding: This work was supported in part by Poliomyelitis Research Foundation (PRF_18/101), National Research Foundation (NRF_118710), National Health Laboratory Service (NHLS) Research Trust (GRANT004_94740), and Flemish Government-Flemish Interuniversity Council (VLIR-IUC) (VLIR-UOS ZIUS2015AP021).

Institutional Review Board Statement: The study was approved by the Sefako Makgatho Health Sciences University Research Ethics Committee (Ref: SMUREC/M/279/2019: PG) and Ref: SMUREC/P/ 75/2016: IR).

Informed Consent Statement: Informed consent was obtained from all subjects involved in the study.

Data Availability Statement: The data analyzed in this study is available upon request from the corresponding author.

Conflicts of Interest: The authors declare no conflict of interest. 


\section{References}

1. Sung, H.; Ferlay, J.; Siegel, R.L.; Laversanne, M.; Soerjomataram, I.; Jemal, A.; Bray, F. Global cancer statistics 2020: GLOBOCAN estimates of incidence and mortality worldwide for 36 cancers in 185 countries. CA Cancer J. Clin. 2021, 71, 209-249. [CrossRef]

2. Sankaranarayanan, R. Screening for cancer in low-and middle-income countries. Ann. Glob. Health 2014, 80, 412-417. [CrossRef]

3. Maseko, F.C.; Chirwa, M.L.; Muula, A.S. Health systems challenges in cervical cancer prevention program in Malawi. Glob. Health Action 2015, 8, 26282. [CrossRef]

4. Hoste, G.; Vossaert, K.; Poppe, W.A. The clinical role of HPV testing in primary and secondary cervical cancer screening. Obstet. Gynecol. Int. 2013. [CrossRef]

5. Arbyn, M.; Ronco, G.; Anttila, A.; Meijer, C.J.; Poljak, M.; Ogilvie, G.; Koliopoulos, G.; Naucler, P.; Sankaranarayanan, R.; Peto, J. Evidence regarding human papillomavirus testing in secondary prevention of cervical cancer. Vaccine 2012, 30, F88-F99. [CrossRef]

6. Wright, T.C.; Stoler, M.H.; Behrens, C.M.; Sharma, A.; Zhang, G.; Wright, T.L. Primary cervical cancer screening with human papillomavirus: End of study results from the ATHENA study using HPV as the first-line screening test. Gynecol. Oncol. 2015, 136, 189-197. [CrossRef]

7. Verdoodt, F.; Jentschke, M.; Hillemanns, P.; Racey, C.S.; Snijders, P.J.F.; Arbyn, M. Reaching women who do not participate in the regular cervical cancer screening programme by offering self-sampling kits: A systematic review and meta-analysis of randomised trials. Eur. J. Cancer 2015, 51, 2375-2385. [CrossRef] [PubMed]

8. Obiri-Yeboah, D.; Adu-Sarkodie, Y.; Djigma, F.; Hayfron-Benjamin, A.; Abdul, L.; Simpore, J.; Mayaud, P. Self-collected vaginal sampling for the detection of genital human papillomavirus (HPV) using care HPV among Ghanaian women. BMC Women's Health 2017, 17, 1-6. [CrossRef] [PubMed]

9. Tranberg, M.; Jensen, J.S.; Bech, B.H.; Blaakær, J.; Svanholm, H.; Andersen, B. Good concordance of HPV detection between cervico-vaginal self-samples and general practitioner-collected samples using the Cobas 4800 HPV DNA test. BMC Infect. Dis. 2018, 18, 1-7. [CrossRef] [PubMed]

10. Petignat, P.; Faltin, D.L.; Bruchim, I.; Tramèr, M.R.; Franco, E.L.; Coutlée, F. Are self-collected samples comparable to physiciancollected cervical specimens for human papillomavirus DNA testing? A systematic review and meta-analysis. Gynecol. Oncol. 2007, 105, 530-535. [CrossRef] [PubMed]

11. Waller, J.; McCaffery, K.; Forrest, S.; Szarewski, A.; Cadman, L.; Austin, J.; Wardle, J. Acceptability of unsupervised HPV self-sampling using written instructions. J. Med. Screen. 2006, 13, 208-213. [CrossRef]

12. Taylor, D.; Lunny, C.; Wong, T.; Gilbert, M.; Li, N.; Lester, R.; Krajden, M.; Hoang, L.; Ogilvie, G. Self-collected versus cliniciancollected sampling for sexually transmitted infections: A systematic review and meta-analysis protocol. Syst. Rev. 2013, 2, 1-6. [CrossRef] [PubMed]

13. Esber, A. Feasibility, validity and acceptability of self-collected samples for human papillomavirus (HPV) testing in rural Malawi. Malawi Med. J. 2018, 30, 61-66. [CrossRef] [PubMed]

14. Asciutto, K.C.; Henningsson, A.J.; Borgfeldt, H.; Darlin, L.; Borgfeldt, C. Vaginal and urine self-sampling compared to cervical sampling for HPV-testing with the cobas $4800 \mathrm{HPV}$ test. Anticancer Res. 2017, 37, 4183-4187. [CrossRef]

15. Arbyn, M.; Smith, S.B.; Temin, S.; Sultana, F.; Castle, P. Detecting cervical precancer and reaching underscreened women by using HPV testing on self samples: Updated meta-analyses. BMJ 2018, 363. [CrossRef]

16. Rossi, P.G.; Fortunato, C.; Barbarino, P.; Boveri, S.; Caroli, S.; Del Mistro, A.; Ferro, A.; Giammaria, C.; Manfredi, M.; Moretto, T.; et al. Self-sampling to increase participation in cervical cancer screening: An RCT comparing home mailing, distribution in pharmacies, and recall letter. Br. J. Cancer 2015, 112, 667-675. [CrossRef]

17. Enerly, E.; Bonde, J.; Schee, K.; Pedersen, H.; Lönnberg, S.; Nygård, M. Self-sampling for human papillomavirus testing among non-attenders increases attendance to the Norwegian cervical cancer screening programme. PLoS ONE 2016, 11, e0151978. [CrossRef] [PubMed]

18. Lim, A.W.; Hollingworth, A.; Kalwij, S.; Curran, G.; Sasieni, P. Offering self-sampling to cervical screening non-attenders in primary care. J. Med. Screen. 2017, 24, 43-49. [CrossRef]

19. National Department of Health. Cervical Cancer Prevention and Control Policy. Pretoria. 2017. Available online: https: / / extranet.who.int/ncdccs/Data/ZAF_B5_cervical\%20cancer\%20policy.pdf (accessed on 18 March 2021).

20. Safaeian, M.; Kiddugavu, M.; Gravitt, P.E.; Ssekasanvu, J.; Murokora, D.; Sklar, M.; Serwadda, D.; Wawer, M.J.; Shah, K.V.; Gray, R. Comparability of self-collected vaginal swabs and physician-collected cervical swabs for detection of human papillomavirus infections in Rakai, Uganda. J. Sex. Transm. Dis. 2007, 34, 429-436. [CrossRef]

21. Mbatha, J.N.; Galappaththi-Arachchige, H.N.; Mtshali, A.; Taylor, M.; Ndhlovu, P.D.; Kjetland, E.F.; Baay, M.F.D.; MkhizeKwitshana, Z.L. Self-sampling for human papillomavirus testing among rural young women of KwaZulu-Natal, South Africa. BMC Res. Notes 2017, 10, 1-8. [CrossRef]

22. Taku, O.; Meiring, T.L.; Gustavsson, I.; Phohlo, K.; Garcia-Jardon, M.; Mbulawa, Z.Z.; Businge, C.B.; Gyllensten, U.; Williamson, A.L. Acceptability of self-collection for human papillomavirus detection in the Eastern Cape, South Africa. PLoS ONE 2020, 15, e0241781. [CrossRef]

23. Haile, E.L.; Cindy, S.; Ina, B.; Belay, G.; geertruyden Jean-Pierre, V.; Sharon, R.; Lisbeth, L.R.; Paul, B.J. HPV testing on vaginal/cervical nurse-assisted self-samples versus clinician-taken specimens and the HPV prevalence, in Adama Town, Ethiopia. Medicine 2019, 98. [CrossRef] 
24. Viviano, M.; Tran, P.L.; Kenfack, B.; Catarino, R.; Akaaboune, M.; Temogne, L.; Foguem, E.T.; Vassilakos, P.; Petignat, P. Self-versus physician-collected samples for the follow-up of human papillomavirus-positive women in sub-Saharan Africa. Int. J. Women's Health 2018, 10, 187. [CrossRef]

25. Jones, H.E.; Allan, B.R.; van De Wijgert, J.H.; Altini, L.; Taylor, S.M.; de Kock, A.; Coetzee, N.; Williamson, A.L. Agreement between self-and clinician-collected specimen results for detection and typing of high-risk human papillomavirus in specimens from women in Gugulethu, South Africa. J. Clin. Microbiol. 2007, 45, 1679-1683. [CrossRef]

26. Phoolcharoen, N.; Kantathavorn, N.; Krisorakun, W.; Sricharunrat, T.; Teerayathanakul, N.; Taepisitpong, C.; Sornsamdang, G.; Krongthong, W.; Saeloo, S. Agreement of self-and physician-collected samples for detection of high-risk human papillomavirus infections in women attending a colposcopy clinic in Thailand. BMC Res. Notes 2018, 11, 1-5. [CrossRef] [PubMed]

27. Onuma, T.; Kurokawa, T.; Shinagawa, A.; Chino, Y.; Yoshida, Y. Evaluation of the concordance in HPV type between self-and physician-collected samples using a brush-based device and a PCR-based HPV DNA test in Japanese referred patients with abnormal cytology or HPV infection. Int. J. Clin. Oncol. 2020, 25, 1854-1860. [CrossRef] [PubMed]

28. Adamson, P.C.; Huchko, M.J.; Moss, A.M.; Kinkel, H.F.; Medina-Marino, A. Acceptability and accuracy of cervical cancer screening using a self-collected tampon for HPV messenger-RNA testing among HIV-infected women in South Africa. PLoS ONE 2015, 10, e0137299. [CrossRef] [PubMed]

29. Senkomago, V.; Ting, J.; Kwatampora, J.; Gukare, H.; Mugo, N.; Kimani, J.; Smith, J.S. High-risk HPV-RNA screening of physicianand self-collected specimens for detection of cervical lesions among female sex workers in Nairobi, Kenya. Int. J. Gynecol. Obstet. 2018, 143, 217-224. [CrossRef]

30. Arbyn, M.; Verdoodt, F.; Snijders, P.J.; Verhoef, V.M.; Suonio, E.; Dillner, L.; Minozzi, S.; Bellisario, C.; Banzi, R.; Zhao, F.H.; et al. Accuracy of human papillomavirus testing on self-collected versus clinician-collected samples: A meta-analysis. Lancet Oncol. 2014, 15, 172-183. [CrossRef]

31. Toliman, P.J.; Kaldor, J.M.; Badman, S.G.; Phillips, S.; Tan, G.; Brotherton, J.M.L.; Saville, M.; Vallely, A.J.; Tabrizi, S.N. Evaluation of self-collected vaginal specimens for the detection of high-risk human papillomavirus infection and the prediction of high-grade cervical intraepithelial lesions in a high-burden, low-resource setting. Clin. Microbiol. Infect. 2019, 25, 496-503. [CrossRef]

32. Sultana, F.; Mullins, R.; English, D.R.; Simpson, J.A.; Drennan, K.T.; Heley, S.; Wrede, C.D.; Brotherton, J.M.; Saville, M.; Gertig, D.M. Women's experience with home-based self-sampling for human papillomavirus testing. BMC Cancer 2015, 15, 1-10. [CrossRef] [PubMed]

33. Kohler, R.E.; Elliott, T.; Monare, B.; Moshashane, N.; Ramontshonyana, K.; Chatterjee, P.; Ramogola-Masire, D.; Morroni, C. HPV self-sampling acceptability and preferences among women living with HIV in Botswana. Int. J. Gynecol. Obstet. 2019, 147, 332-338. [CrossRef] [PubMed]

34. Saidu, R.; Moodley, J.; Tergas, A.; Momberg, M.; Boa, R.; Wright, T.; Campbell, S.; Svanholm-Barrie, C.; Persing, D.; Kuhn, L.; et al. South African women's perspectives on self-sampling for cervical cancer screening: A mixed-methods study. S. Afr. Med. J. 2019, 109, 47-52. [CrossRef] [PubMed]

35. Fokom Domgue, J.; Futuh, B.; Ngalla, C.; Kakute, P.; Manjuh, F.; Manga, S.; Nulah, K.; Welty, E.; Schmeler, K.; Welty, T. Feasibility of a community-based cervical cancer screening with "test and treat" strategy using self-sample for an HPV test: Experience from rural Cameroon, Africa. Int. J. Cancer 2020, 147, 128-138. [CrossRef] [PubMed] 